Article Type: Reviews

Reviews

Fish-smart seawalls: a decision tool for adaptive management of marine infrastructure Rebecca L Morris ${ }^{1{ }^{+*}}$, Augustine G Porter ${ }^{1}$, Will F Figueira ${ }^{1,2}$, Ross A Coleman ${ }^{1}$, Emily K Fobert $^{3}$, and Renata Ferrari ${ }^{1,2}$

${ }^{1}$ Coastal and Marine Ecosystems Group, School of Life and Environmental Sciences, The University of Sydney, Sydney, Australia; ${ }^{\dagger}$ current address: National Centre for Coasts and Climate, School of BioSciences, The University of Melbourne, Melbourne, Australia *(rebecca.morris@unimelb.edu.au); '2Sydney Institute of Marine Sciences, Chowder Bay, Mosman, Australia; ${ }^{3}$ School of BioSciences, The University of Melbourne, Melbourne, Australia

\title{
Running heads:
}

RL Morris et al.

Fish-smart marine infrastructure

Infrastructure is increasingly being built in marine habitats, with extensive ecological consequences for benthic and fish assemblages alike. The practice of ecological engineering attempts to mitigate the negative impacts of infrastructure through the design of artificial structures that benefit both humans and nature. Although research has primarily focused on the benefits for invertebrates and algae, fish also respond to changes in habitat complexity and benthic biodiversity. We surveyed the scientific literature on naturral and artificial reefs to identify key habitat features that fish respond to, and propose a decision tool for ecologists and managers to tailor the structural complexity of marine infrastructure for fish. Inevitably, natural habitats will increasingly be replaced with artificial ones, making ecologically sensitive designs essential for maintaining biodiversity and ecosystem services. Using lessons from natural and artificial reefs, we show that existing and new infrastructure could be

This is the author manuscript accepted for publication and has undergone full peer review but has not been through the copyediting, typesetting, pagination and proofreading process, which may lead to differences between this version and the Version of Record. Please cite this article as doi: 10.1002/FEE.1809 


\section{designed not only to reduce negative impacts but also to foster positive effects on fish assemblages.}

Front Ecol Environ 2018;

\section{In a nutshell:}

- Ecological engineering can mitigate the negative impacts of built infrastructure on marine assemblages

- Fishes are known to respond to certain habitat features on both natural and artificial reefs

- Knowledge gained from the association of fish with natural and artificial habitat features can be applied in marine management to create "fish friendly" infrastructure (ie that enhances local diversity and productivity of fishes)

Coastal urbanization affects marine systems through the construction of artificial infrastructure. More than $50 \%$ of foreshores in selected estuaries worldwide are defended with hard engineering, such as seawalls and breakwaters (eg in the US and Australia; Figure 1a; Dugan et al. 2011;), but infrastructure inserted into marine ecosystems is not limited to coastal armoring; other examples include structures intended for commercial, residential, or recreational purposes (eg marinas, pilings, pontoons, swimming enclosures, airports, "canal estates"), offshore energy installations (eg oil rigs, wind farms), and fishery-based features (eg aquaculture farms, fish aggregation devices) (Dafforn et al. 2015b). In addition, the deployment of artificial reefs is used in marine management and tourism worldwide as a tool to enhance commercial fisheries, provide sites for recreational diving and snorkeling, and mitigate impacts to natural reef habitat (reviewed in Baine 2001; Feary et al. 2011). Although artificial reefs can be considered to be a human construct in the marine environment (Feary et al. 2011; Dafforn et al. 2015b), they differ from other marine infrastructure in that these reefs are purposely designed for ecological effects, whereas in general, marine infrastructure is engineered primarily for socioeconomic purposes. The scientific literature on how fish assemblages are influenced by artificial reefs is extensive, but little research has been conducted on how they are influenced by marine infrastructure. Here, we consider marine infrastructure separately from artificial reefs.

Coastal urban sprawl often drives the loss of important coastal and marine habitats and the addition of hard substrata for colonization by reef species (Bulleri and Chapman 
2010). Despite an increasing amount of research demonstrating the substantial ecological impacts of these artificial structures (see Bulleri and Chapman [2010] for a review), coastlines continue to be altered with few changes in practices to manage such impacts. Moreover, construction of marine infrastructure is likely to expand in the future due to climate change, which will require improved defenses for coastal cities against sea-level rise and more frequent and intense storm events (IPCC 2014). "Ecological engineering" or "ecoengineering" is the attempt to redesign built infrastructure to be multifunctional, benefiting both humans and nature (Chapman and Underwood 2011; Dafforn et al. 2015a). For instance, the addition of complex surfaces and novel habitats to infrastructure can contribute to the rehabilitation of species living on these structures (reviewed by Dafforn et al. 2015a). To date, eco-engineering research has been primarily directed toward enhancing benthic diversity. However, increased benthic diversity and habitat structural complexity (hereafter, "habitat or structural complexity") added through eco-engineering has recently been shown to influence fish assemblages associated with artificial habitats (Toft et al. 2013; Sella and Perkol-Finkel 2015; Morris et al. 2017a). In this paper, we first review the consequences of marine infrastructure for fish. By using examples from investigations on natural reefs and artificial reef design, we then propose a decision tool to guide management and future research in eco-engineering toward not only reducing negative impacts, but also fostering benefits of existing and new artificial structures for fish populations.

\section{Consequences of marine infrastructure for fish assemblages}

Much of the literature on fish and marine infrastructure has documented patterns, numbers and/or abundance of fish species around infrastructure, and made comparisons between adjacent habitats or natural hard substrata (WebTable 1). Coastal (eg breakwaters) and offshore (eg oil rigs) infrastructure has been colonized by diverse fish assemblages (Figure 1c; Rilov and Benayahu 1998), including species of commercial value (Pradella et al. 2014) and those that are in decline in their natural habitat (Love et al. 2006). Marine infrastructure is often built on soft sediments, and in comparison with the adjacent soft substrata or open water, a localized increase in fish biodiversity can occur in response to the construction of some types of infrastructure (Guidetti 2004). However, increases in fish diversity are typically restricted to species associated with the newly created reef rather than among the pre-existing soft-bottom assemblage. The creation of hard infrastructure in the marine environment often comes at the loss of soft-bottom habitat and its associated fish assemblage (Heery et al. 2017). Similarly, replacing saltmarsh habitat with coastal armoring can have 
negative impacts on the early-life stages of fish (Peterson et al. 2000) and potentially affect connectivity between habitats (Bishop et al. 2017). For instance, artificial structures can facilitate the expansion of invasive benthic species, including tunicates (Airoldi et al. 2015) and fishes (eg lionfish [Pterois spp]; Smith and Shurin 2010) by providing habitat for colonization. Furthermore, the presence of piers along shorelines has consistently been shown to have negative impacts on the number of fish species, as well as on fish abundance, behavior, and growth. This is likely due to the creation of intensely dark environments, which can reduce prey availability, impair visual-based behaviors, and constrain movement (Munsch et al. 2017). Marine infrastructure can be dominated by a few groups of fish (eg Rilov and Benayahu 1998) and often does not have the same assemblage of fishes in comparison to natural reefs (eg Burt et al. 2009). Therefore, such infrastructure should not be considered a surrogate for natural reefs.

As with artificial reefs, the degree to which marine infrastructure contributes to the production of fish biomass remains a topic of debate (Bohnsack 1989; Macreadie et al. 2011). For example, at small spatial extents, increased densities of fish were observed aggregated near individual offshore wind turbines, whereas no effects on fish abundance were seen at larger spatial extents when comparing areas with wind turbines to reference sites without turbines (Bergstrom et al. 2013). If hard-bottomed habitat is not a limiting factor for fish, then adding artificial structures may only result in the attraction and aggregation of fish (the "attraction hypothesis"; Bohnsack 1989). This can exacerbate sustainability problems in already overexploited fisheries by causing fish to be more easily caught (Bohnsack 1989) or if individual performance (growth and reproduction) is lower on the artificial structure than on accessible natural reefs, although this may not always be the case (Smith et al. 2015). Unlike attraction of fish, production of fish is difficult to quantify and requires long-term monitoring of populations over sufficient spatial and temporal scales (Macreadie et al. 2011). Offshore oil rigs in California are considered to support high levels of fish productivity, primarily due to the recruitment and subsequent growth of rockfish species, and therefore provide evidence for the fish production rather than the attraction hypothesis (Love et al. 2007).

\section{Eco-engineering to mitigate negative impacts of marine infrastructure}

Termed "reconciliation ecology" (Rosenzweig 2003), the ecologically sensitive design of built infrastructure is not a new concept, but it has received comparatively little attention in marine as opposed to terrestrial systems. Eco-engineering research in the marine environment 
has been primarily directed toward developing benefits for benthic invertebrate and/or algal diversity through additive (attachment of protruding structures that are either abiotic or biotic) or subtractive (drilling or removal of substrata) methods to increase surface area and/or habitat complexity (Figure 1, b and d; Strain et al. 2017b). However, there is a knowledge gap regarding the effects of eco-engineered marine infrastructure on non-sessile species, such as fish.

A small number of studies have demonstrated that increased benthic diversity and structural complexity provided by eco-engineered habitats can increase the number of species and abundance of fish associated with marine infrastructure (Panel 1; Toft et al. 2013; Sella and Perkol-Finkel 2015; Strain et al. 2017a). This benefit does not seem to accrue if complexity features derive from the presence of additional soft structures (eg coir turf, a natural coconut fiber matting), as these had no effect on visiting fish assemblages (Morris et al. 2017b). Similarly, the addition of complexity through the incorporation of holes in the foundations of wind turbines did not have an effect on fish abundance, which may suggest a species-specific response (Langhamer and Wilhelmsson 2009).

Few studies have examined the particular influence of features of marine infrastructure on local fish populations. Greater topographical complexity and cover of complex epibiota has, however, been found to have a positive effect on the number of species and abundance of fish around marine infrastructure (Rilov and Benayahu 1998; Clynick et al. 2007). Love and York (2006) identified a positive relationship between the response of fish species that typically associate with natural rocky outcrops and the amount of bottom horizontal beam exposed to the sediment at oil platforms, concluding that sheltering habitat was an important feature of man-made reefs. The vertical relief of infrastructure may also influence fish recruitment, with greater recruitment occurring on structures that span the entire water column (Rilov and Benayahu 1998). Despite the lack of research focusing on the effects of marine infrastructure on fish assemblages, the design of multipurpose marine infrastructure for fish may be informed by existing observational and manipulative studies at natural and purposely designed artificial reefs.

\section{Lessons learned from natural reefs}

In marine systems, environmental variables that influence fish assemblages differ at large (beyond hundreds of meters) and small $(<100 \mathrm{~m})$ spatial extents. For instance, at large spatial extents, fish populations are strongly related to depth and habitat type, with distinct communities occurring at different depths and habitats (Hamilton et al. 2010; Fitzpatrick et 
al. 2012). At smaller spatial extents - within a reef patch, for instance - fish assemblages are affected by variables such as habitat complexity (Harborne et al. 2012), and benthic cover and diversity (Harborne et al. 2011). In general, individual instances of marine infrastructure cannot modify the marine environment over large spatial extents, with the exception of adding habitat that contributes to the spatial structure of marine metapopulations (ie a group of populations of a species separated by space but connected by dispersal). Thus, here we will focus on the environmental features that operate over small spatial extents and that can be easily manipulated when constructing artificial structures to influence fish assemblages.

Structural complexity is the physical three-dimensional structure of a habitat, and it provides a variety of resources to organisms in marine ecosystems (see review by Graham and Nash 2013). Structural complexity affects fish assemblages and community composition by providing refuge and physical habitat for benthic communities, providing fish with both primary and secondary resources, such as food and shelter from both biological (eg predators) and environmental (eg wave exposure) stressors (Harborne et al. 2011). Fish behavior, and therefore key ecological processes, are also affected by structural complexity; for example, some herbiyores and planktivores prefer less complex areas where they can forage while simultaneously monitoring their surroundings for threats (Rilov et al. 2007), although some species may forage within more structurally complex habitats when predation risk is high (Holbrook and Schmitt 1988). The relationship between fish abundance and structural complexity may be influenced by many factors, including body size, home range, fine-scale mobility, trophic preference, and life-history traits (Bozec et al. 2013). Benthic and fish diversity can be enhanced through the contribution of structural complexity to habitat diversity and resource partitioning (Risk 1972). Structural complexity is one of the most important environmental variables affecting fish across small spatial extents, and is therefore a critical factor to consider in the design of marine infrastructure.

Numerous measureable components of structural complexity have been described, the ecological importance of which are well understood in some cases. For instance, features of natural reefs that have a relationship with associated fish assemblages include the density and size of shelters; Vertical relief; and the rugosity index (a measure of substratum complexity, sensu Risk 1972) (WebTable 2; eg Gratwicke and Speight 2005); likewise, there is a positive relationship between shelter density/size and fish density/size on coral reefs, with larger shelters supporting larger and disproportionately more fish (Menard et al. 2012). On temperate reefs, structural complexity is often created or enhanced by macroalgal growth, and this biotic structure can interact with the abiotic topography of the reef to affect the fish 
assemblage. For example, the positive relationship between large-bodied fish and macroalgal stipe density (the stipe is a stem-like algal structure) on temperate rocky reefs was weakened by increasing reef rugosity, thereby altering the size-structure of the fish assemblages (Trebilco et al. 2015). Regardless of its source (abiotic or biotic), structural complexity can influence fish in both positive and negative directions, and different functional groups are affected to different extents by complexity (Rilov et al. 2007).

Structural complexity is directly related to benthic assemblage composition (eg Ferrari et al. 2016), which in turn determines fish diversity and abundance (Harborne et al. 2011, 2012). For instance, the number of fish species was positively correlated with the number of benthic growth forms in different habitats in the Caribbean, whereas height of the habitat was important for fish abundance (Gratwicke and Speight 2005). In particular, habitat structures that are at least $50 \mathrm{~cm}$ in height are strongly related to high abundance of reefassociated fish across different habitats and depth gradients (Harborne et al. 2012). In temperate reefs, where macroalgae provide important physical structure, fish species richness, diversity, and abundance, along with recruitment of many species, are all positively related to the density (Fobert and Swearer 2017) and height (Levin and Hay 1996) of macroalgal stipes, as well as to the composition of the algal canopy (Cheminée et al. 2013).

Structures that provide shade have also been linked to fish abundance and diversity; this relationship is positive in shallow tropical reefs due to protection from solar irradiance (Kerry and Bellwood 2015), but can be negative in some temperate systems (eg under piers, as described above; Munsch et al. 2017), highlighting the importance of considering the context (eg tropical versus temperate; shallow water versus deep water) when designing artificial structures for fish assemblages. To summarize, properties such as topographical complexity, benthic diversity, presence and size of shelters, and vertical relief have major effects on fish in natural systems (Table 1), and are all aspects that have the potential to be modified when designing marine infrastructure. Given that different groups can be positively or negatively affected by particular properties, management goals should be defined at the start of a project (see below).

Although we have identified structural complexity as a dominant factor that influences fish assemblages, the value of marine infrastructure for fish will also depend on the seascape composition, as in natural systems. For instance, because many fish display habitat shifts with age, it is necessary to maintain connectivity between the habitats required at different life stages (Fitzpatrick et al. 2012). Changes in environmental gradients due to factors such as depth and wave exposure also promote differences in fish assemblages 
(Fitzpatrick et al. 2012; Borland et al. 2017). Thus, the context in which the infrastructure is placed needs to be considered, and will also determine the targets that can be achieved.

\section{Lessons learned from artificial reefs}

Research on natural reefs is generally limited to correlative studies between fish and habitat features, due to the difficulty in manipulating natural substrata (but see Cheminée et al. 2013). In contrast, artificial reefs can be easily manipulated at the design stage, and this can be useful in determining causation between habitat features and effects on fish assemblages. Design is a major theme in the artificial reef literature, and can include a variety of attributes such as material used, substratum complexity, vertical relief, size, and spatial configuration (WebTable 2; Baine 2001). There are several aspects of a custom-built artificial reef that could be manipulated and, in theory, influence local fish assemblages (Table 1). The above aspects are of particular interest in this review, because they could easily be controlled when materials are deployed, and are equally applicable to the design of marine infrastructure.

One of the most thoroughly studied aspects of artificial reef design is the effect of interstitial spaces. Interstices (the spaces, gaps, or holes in or between substrata) can be important drivers of local fish assemblages by providing shelter (Sherman et al. 1999). Reef units that had no gaps had fewer fish species and lower fish abundance (Kellison and Sedberry 1998), with the number of fish increasing with the number of gaps provided (Gascon and Miller 1982). Conversely, some studies, including a recent meta-analysis (Strain et al. 2017b), have indicated that reef holes have no effect on species richness, which suggests that the use of holes needs to be considered on a site-specific basis (WebTable 2; Strain et al. 2017b). However, the effect of interstice may be more prevalent when different groups within the assemblage are studied. Some studies have confirmed that the number of species, as well as the abundance and size of fish, differ when larger or smaller shelters are used. For example, Hixon and Beets (1989) concluded that fish size corresponded with refuge size (ie bigger fishes used larger holes), while other studies have demonstrated no difference between treatments using different-sized interstices (Sherman et al. 1999). The effect of interstitial spaces can be complicated by trophic interactions, with shelters for small fish becoming more important where there are higher numbers of predators (Gascon and Miller 1982; Hixon and Beets 1989). Consideration of ecological interactions is therefore also important when designing marine infrastructure, particularly if there are species-specific management objectives. 
In addition to interstitial spaces, other topographical aspects, such as vertical relief, can affect the associated fish assemblages directly (eg recruitment; Wilhelmsson et al. 2006) and/or indirectly (eg benthic assemblage; Bulleri and Chapman 2010). For instance, one of the largest artificial reef experiments, which was conducted on reefs adjacent to the San Onofre Nuclear Generating Station in southern California, tested the relative effectiveness of several aspects of reef design on fish assemblages. This study found that characteristics contributing to the physical footprint of the reef (ie the amount of bottom covered by hard substrate) had a substantially positive influence on the density, richness, and biomass of the fish assemblage, as well as on young-of-year recruitment, whereas the same metrics were relatively insensitive to material type (quarry rock or recycled concrete rubble) (Reed et al. 2006). However, research elsewhere has indicated material type to be of importance, with the number of some species of fish and their abundance differing between reefs made of different materials (eg tires, wood, metal, sandstone; Chapman and Clynick 2006). The addition of hard floating structures (eg fish aggregating devices; Kellison and Sedberry 1998) to reefs can also increase the diversity and abundance of fish. Furthermore, high-relief structures are known to improve recruitment (Rilov and Benayahu 2002) and support greater numbers of planktivores, possibly due to the creation of favorable flow patterns (Wilhelmsson et al. 2006). A common practice among artificial reef studies is to compare the fish assemblage to that on nearby natural reefs. An important and intuitive trend here is that where the topography of artificial reefs is similar to that of adjacent natural reefs (low relief, low rugosity, and composed of small- to medium-sized boulders), local fish assemblages also tend to be similar (Granneman and Steele 2015).

Spatial layout and reef size are additional drivers of fish assemblages; abundance and diversity (per unit of habitat) appear to increase with more numerous, smaller reefs (Bohnsack et al. 1994). Isolated reefs have also been shown to have greater diversity and biomass per unit area (Belmaker et al. 2005). Larger reefs, on the other hand, tend to support larger individual fishes (Bohnsack et al. 1994). The layout of a reef or piece of infrastructure will also have implications for species associated with ecotone habitats (Bellquist et al. 2008). These trade-offs reinforce the importance of framing infrastructure works in the context of specific ecological objectives.

\section{Application to the management of marine infrastructure}

This review has summarized a broad range of information useful for "fish friendly" design of marine infrastructure from studies of both natural and artificial reefs (see Table 1 for a 
summary). Generally speaking, the effects of different habitat features on fish were consistent across natural and artificial habitats, which is beneficial for the application of this information to marine infrastructure. The only parameter where the literature from natural and artificial reefs disagreed was the effect of diversity of abiotic/biotic structures on species richness, which was positive for natural reefs but had no effect for artificial reefs (Table 1). Although there was a trend toward increasing fish species richness with diversity of benthic growth forms at artificial reefs, this trend was not statistically significant (WebTable 2).

There was a lack of information regarding some features of artificial or natural habitats (Table 1). In particular, data were focused on species richness and abundance of the fish assemblages, with fewer parameters tested for specific groups of fish (eg at a particular trophic level). If the management objective is more specific than simply increasing fish diversity generally, then there is less certainty about aspects of habitat design that will target certain groups (WebFigure 1, pink boxes). Targeting functional groups of fish may be desirable, as research has shown that enhancing functional rather than taxonomic diversity can increase the ecosystem services and productivity of assemblages (Stuart-Smith et al. 2013). Furthermore, in some cases, contrasting information was found within either artificial or natural reefs. This suggests that management initiatives may be context dependent (Chapman and Underwood 2011), and highlights the importance of evaluating projects on a case-by-case basis.

The successful application of this information in future projects will have, at its core, the early and specific identification of the desired properties of the fish assemblage at the structure (WebFigure 1, diamonds). On the basis of our literature review, we propose that common objectives for enhancement include fish biodiversity generally, specific fish groups, or even a particular fish species. For each target, there are general categories of ecological considerations that should be included in decision making; for instance, when targeting a particular fish species, one needs to identify whether one or more life stages are targeted (eg nursery habitat, spawning habitat) and the resources required at each life stage (WebFigure 1, yellow boxes). The ecological bases for these resources need to be known in order for them to be enhanced (see Panel 2 for an example). In all cases, the availability of required supporting habitats must be evaluated, and if they are unavailable, flexibility in the location of the structure will have to be considered (WebFigure 1, yellow and purple boxes). If there is flexibility with regard to the location, structures could be positioned relative to natural/artificial reefs and other supporting habitats (eg salt marsh, sedimentary habitats) or along varying environmental gradients to promote greater diversity of species (WebFigure 1, 
purple boxes). One should also consider the variety and abundance of structural features needed to achieve the targeted objectives (Table 1; WebFigure 1, blue and pink boxes).

Once the biological target or targets have been identified, it is then necessary to assess the structural requirements against the design limitations (engineering, financial, political, social) of the project. For instance, if the project involves coastal armoring, what level of slope is possible? Must the structure be one contiguous piece? How large or small can holes be (if any are possible) without interfering with its functional role? What is the additional financial cost (if any) of changing the design of the structure, and is this within budget? Given that artificial structures are human-driven insertions into the environment, their social value has been a target for recent research (Morris et al. 2016) due to the importance of public support for the success of eco-engineering projects. A public consultation may be a required step prior to eco-engineering projects. Once limitations have been identified, it is necessary to review and possibly revise the biological targets in light of these limitations, an important iterative step in which the expectation for the resulting fish assemblage and design of the structure must be revised so they are complementary. This is the time for creativity and synergies, where ecological requirements can be viewed as opportunities for innovation. Many projects seek to satisfy specific biological or ecological requirements by creating novel artistic or architectural features that can, for example, provide increased structural complexity on seawalls or even control the amount of shading under wharfs through the use of transparent or opaque ground panels, depending on desired outcomes (as in the juvenile salmon eco-engineering case study described in Panel 1).

The final component for the successful application of "fish friendly" design to marine infrastructure is ongoing monitoring and adaptive management (WebFigure 1, red box). It is critical that the original ecological objectives of the project are assessed and, where possible, adaptive management options and trigger points incorporated into the design. For instance, it may be possible to change the design of panels of differing complexity that have been retrofitted onto artificial structures if monitoring data suggest that the original objectives are not being met. The combination of monitoring and adaptive management will not only enhance the probability of success of individual projects but can also inform other projects.

\section{Conclusions}

While much research has focused on the effects of habitat features on fish assemblages in natural and artificial reefs, relatively little is known about the association of fish with marine infrastructure. Aligning with previous guidance for eco-engineering targeted at benthic 
organisms, we have identified key habitat features that are important for fish and proposed a decision tool for incorporating these features into marine infrastructure to manage fish populations.

Our goal was to capture aspects of complexity that can be used directly to inform management. Although manipulation of habitat complexity is likely to have an impact on fish assemblages, there is a major knowledge gap regarding the fitness consequences for fish associated with artificial structures. The impacts of eco-engineering on metapopulations are unknown, as is the scale of enhancement needed to provide any measurable difference in fish populations. This has been a contested subject in the artificial reef literature for many years (Bohnsack 1989), and is an important consideration in cases where marine infrastructure represents a large portion of available habitat for a species within a particular area.

Nevertheless, applied research to measure and construct aspects of complexity is likely to be invaluable in the management of current and future marine infrastructure. Moreover, successful implementation of physical structures to support targeted ecological impacts for fish communities could contribute substantially to a large number of policy objectives worldwide, in particular the promotion of sustainable development and maintenance/rehabilitation of biodiversity and ecosystem functioning (Dafforn et al. 2015b). Interdisciplinary collaboration between scientists, managers, engineers, and other stakeholders will provide the opportunity to fill existing knowledge gaps.

\section{Acknowledgements}

RLM was supported by a grant from The Sydney Coastal Councils Group through funding from the Australian Government (to S Golding, RAC, RLM, and J Martin).

\section{References}

Airoldi L, Turon X, Perkol-Finkel S, et al. 2015. Corridors for aliens but not for natives: effects of marine urban sprawl at a regional scale. Divers Distrib 21: 755-68.

Baine M. 2001. Artificial reefs: a review of their design, application, management and performance. Ocean Coast Manage 44: 241-59.

Bellquist LF, Lowe CG, and Caselle JE. 2008. Fine-scale movement patterns, site fidelity, and habitat selection of ocean whitefish (Caulolatilus princeps). Fish Res 91: 325-35.

Belmaker J, Shashar N, and Ziv Y. 2005. Effects of small-scale isolation and predation on fish diversity on experimental reefs. Mar Ecol-Prog Ser 289: 273-83. 
Bergstrom L, Sundqvist F, and Bergstrom U. 2013. Effects of an offshore wind farm on temporal and spatial patterns in the demersal fish community. Mar Ecol-Prog Ser $\mathbf{4 8 5}$ : 199-210.

Bishop MJ, Mayer-Pinto M, Airoldi L, et al. 2017. Effects of ocean sprawl on ecological connectivity: impacts and solutions. J Exp Mar Biol Ecol 492: 7-30.

Bohnsack JA. 1989. Are high densities of fishes at artificial reefs the result of habitat limitation or behavioral preference? B Mar Sci 44: 631-45.

Bohnsack JA, Harper DE, McClellan DB, et al. 1994. Effects of reef size on colonization and assemblage structure of fishes at artificial reefs of southeastern Florida, USA. B Mar Sci 55: 796-823.

Borland HP, Schlacher TA, Gilby BL, et al. 2017. Habitat type and beach exposure shape fish assemblages in the surf zones of ocean beaches. Mar Ecol-Prog Ser 570: 203-11.

Bozec YM, Yakob L, Bejarano S, et al. 2013. Reciprocal facilitation and non-linearity maintain habitat engineering on coral reefs. Oikos 122: 428-40.

Bulleri F and Chapman MG. 2010. The introduction of coastal infrastructure as a driver of change in marine environments. J Appl Ecol 47: 26-35.

Burt J, Bartholomew A, Usseglio P, et al. 2009. Are artificial reefs surrogates of natural habitats for corals and fish in Dubai, United Arab Emirates? Coral Reefs 28: 663-75.

Chapman M and Clynick B. 2006. Experiments testing the use of waste material in estuaries as habitat for subtidal organisms. J Exp Mar Biol Ecol 338: 164-78.

Chapman MG and Underwood AJ. 2011. Evaluation of ecological engineering of "armoured" shorelines to improve their value as habitat. J Exp Mar Biol Ecol 400: 302-13.

Cheminée A, Sala E, Pastor J, et al. 2013. Nursery value of Cystoseira forests for Mediterranean rocky reef fishes. J Exp Mar Biol Ecol 442: 70-79.

Clynick BG, Chapman MG, and Underwood AJ. 2007. Effects of epibiota on assemblages of fish associated with urban structures. Mar Ecol-Prog Ser 332: 201-10.

Cordell JR, Toft JD, Munsch SH, et al. 2017. Benches, beaches, and bumps: how habitat monitoring and experimental science can inform urban seawall design. In: Bilkovic DM, Mitchell MR, Toft JD, and La Peyre MK (Eds). Living shorelines: the science and management of nature-based coastal protection. Boca Raton, FL: CRC Press.

Dafforn KA, Glasby TM, Airoldi L, et al. 2015a. Marine urbanization: an ecological framework for designing multifunctional artificial structures. Front Ecol Environ 13: 8290. 
Dafforn KA, Mayer-Pinto M, Morris RL, et al. 2015b. Application of management tools to integrate ecological principles with the design of marine infrastructure. J Environ Manage 158: $61-73$.

Dugan JE, Airoldi L, Chapman MG, et al. 2011. Estuarine and coastal structures: environmental effects, a focus on shore and nearshore structures. In: Wolanski E and McLusky D (Eds). Treatise on estuarine and coastal science, vol 8: human-induced problems. London, UK: Elsevier.

Feary DA, Burt JA, and Bartholomew A. 2011. Artificial marine habitats in the Arabian Gulf: review of current use, benefits and management implications. Ocean Coast Manage 54: $742-49$

Ferrari R, Bryson M, Bridge T, et al. 2016. Quantifying the response of structural complexity and community composition to environmental change in marine communities. Global Change Biol 22: 1965-75.

Fitzpatrick BM, Harvey ES, Heyward AJ, et al. 2012. Habitat specialization in tropical continental shelf demersal fish assemblages. PLoS ONE 7: e39634.

Fobert E and Swearer S. 2017. The nose knows: linking sensory cue use, settlement decisions, and post-settlement survival in a temperate reef fish. Oecologia 183: 1041-51.

Gascon D and Miller RA. 1982. Space utilization in a community of temperate reef fishes inhabiting small experimental artificial reefs. Can J Zool 60: 798-806.

Goff M. 2010. Evaluating habitat enhancements of an urban intertidal seawall: ecological responses and management implications (MS thesis). Seattle, WA: University of Washington.

Graham N and Nash K. 2013. The importance of structural complexity in coral reef ecosystems. Coral Reefs 32: 1-12.

Granneman JE and Steele MA. 2015. Effects of reef attributes on fish assemblage similarity between artificial and natural reefs. ICES J Mar Sci 72: 2385-97.

Gratwicke B and Speight MR. 2005. The relationship between fish species richness, abundance and habitat complexity in a range of shallow tropical marine habitats. J Fish Biol 66: 650-67.

Guidetti P. 2004. Fish assemblages associated with coastal defence structures in southwestern Italy (Mediterranean Sea). J Mar Biol Assoc UK 84: 669-70.

Hamilton SL, Caselle JE, Malone DP, et al. 2010. Incorporating biogeography into evaluations of the Channel Islands marine reserve network. P Natl Acad Sci USA 107: 18272-77. 
Harborne AR, Mumby PJ, and Ferrari R. 2012. The effectiveness of different meso-scale rugosity metrics for predicting intra-habitat variation in coral-reef fish assemblages. Environ Biol Fish 94: 431-42.

Harborne AR, Mumby PJ, Kennedy EV, et al. 2011. Biotic and multi-scale abiotic controls of habitat quality: their effect on coral-reef fishes. Mar Ecol-Prog Ser 437: 201-14.

Heery EC, Bishop MJ, Critchley L, et al. 2017. Identifying the consequences of ocean sprawl for sedimentary habitats. J Exp Mar Biol Ecol 492: 31-38.

Hixon MA and Beets JP. 1989. Shelter characteristics and Caribbean fish assemblages: experiments with artificial reefs. B Mar Sci 44: 666-80.

Holbrook SJ and Schmitt RJ. 1988. Effects of predation risk on foraging behavior: mechanisms altering patch choice. J Exp Mar Biol Ecol 121: 151-63.

IPCC (Intergovernmental Panel on Climate Change). 2014. Climate change 2014: synthesis report. Contribution of Working Groups I, II, and III to the Fifth Assessment Report of the Intergovernmental Panel on Climate Change. Geneva, Switzerland: IPCC.

Kalatzis A and Baker L. 2010. Bream. Sydney, Australia: State of New South Wales and Industry \& Investment NSW.

Kellison TG and Sedberry GR. 1998. The effects of artificial reef vertical profile and hole diameter on fishes off South Carolina. B Mar Sci 62: 763-80.

Kerry J and Bellwood D. 2015. The functional role of tabular structures for large reef fishes: avoiding predators or solar irradiance? Coral Reefs 34: 1-10.

Langhamer O and Wilhelmsson D. 2009. Colonisation of fish and crabs of wave energy foundations and the effects of manufactured holes - a field experiment. Mar Environ Res 68: $151-57$.

Levin PS and Hay ME. 1996. Responses of temperate reef fishes to alterations in algal structure and species composition. Mar Ecol-Prog Ser 134: 37-47.

Love MS and York A. 2006. The relationships between fish assemblages and the amount of bottom horizontal beam exposed at California oil platforms: fish habitat preferences at man-made platforms and (by inference) at natural reefs. Fish B-NOAA 104: 542-49.

Love MS, Brothers E, Schroeder DM, et al. 2007. Ecological performance of young-of-theyear blue rockfish (Sebastes mystinus) associated with oil platforms and natural reefs in California as measured by daily growth rates. B Mar Sci 80: 147-57.

Love MS, Schroeder DM, Lenarz W, et al. 2006. Potential use of offshore marine structures in rebuilding an overfished rockfish species, bocaccio (Sebastes paucispinis). Fish BNOAA 104: 383-90. 
Macreadie PI, Fowler AM, and Booth DJ. 2011. Rigs-to-reefs: will the deep sea benefit from artificial habitat? Front Ecol Environ 9: 455-61.

Menard A, Turgeon K, Roche DG, et al. 2012. Shelters and their use by fishes on fringing coral reefs. PLoS ONE 7: e38450.

Morris RL, Deavin G, Hemelryk DS, et al. 2016. Eco-engineering in urbanised coastal systems: consideration of social values. Ecol Manag Restor 17: 33-39.

Morris RL, Chapman MG, Firth LB, et al. 2017a. Increasing habitat complexity on seawalls: investigating large- and small-scale effects on fish assemblages. Ecol Evol 7: 9567-79.

Morris RL, Golding S, Dafforn KA, et al. 2017b. Can coir increase native biodiversity and reduce colonisation of non-indigenous species in eco-engineered rock pools? Ecol Eng; doi.org/10.1016/j.ecoleng.2017.06.038.

Munsch SH, Cordell JR, and Toft JD. 2017. Effects of shoreline armouring and overwater structures on coastal and estuarine fish: opportunities for habitat improvement. $J$ Appl Ecol 54: 1373-84.

Peterson MS, Comyns BH, Hendon JR, et al. 2000. Habitat use by early life-history stages of fishes and crustaceans along a changing estuarine landscape: differences between natural and altered shoreline sites. Wetl Ecol Manag 8: 209-19.

Pradella N, Fowler AM, Booth DJ, et al. 2014. Fish assemblages associated with oil industry structures on the continental shelf of north-western Australia. J Fish Biol 84: 247-55.

Reed DC, Schroeter SC, Huang D, et al. 2006. Quantitative assessment of different artificial reef designs in mitigating losses to kelp forest fishes. B Mar Sci 78: 133-50.

Rilov G and Benayahu Y. 1998. Vertical artificial structures as an alternative habitat for coral reef fishes in disturbed environments. Mar Environ Res 45: 431-51.

Rilov G and Benayahu Y. 2002. Rehabilitation of coral reef-fish communities: the importance of artificial-reef relief to recruitment rates. B Mar Sci 70: 185-97.

Rilov G, Figueira WF, Lyman SJ, et al. 2007. Complex habitats may not always benefit prey: linking visual field with reef fish behavior and distribution. Mar Ecol-Prog Ser 329: 22538.

Risk MJ. 1972. Fish diversity on a coral reef in the Virgin Islands. Atoll Res Bull 153: 1-6.

Rosenzweig ML. 2003. Reconciliation ecology and the future of species diversity. Oryx 37: 194-205.

Rowling K, Hegarty A, and Ives M (Eds). 2010. Status of fisheries resources in NSW 2008/09. Cronulla, Australia: NSW Industry \& Investment. 
Sella I and Perkol-Finkel S. 2015. Blue is the new green - ecological enhancement of concrete based coastal and marine infrastructure. Ecol Eng 84: 260-72.

Sherman RL, Gilliam D, and Spieier R. 1999. Effects of refuge size and complexity on recruitment and fish assemblage formation on small artificial reefs. Oceanogr Faculty Proc Pres Speech Lect Paper 67. http://nsuworks.nova.edu/occ_facpresentations/67. Viewed 12 Jan 2018.

Smith JA, Lowry MB, and Suthers IM. 2015. Fish attraction to artificial reefs not always harmful: a simulation study. Ecol Evol 5: 4590-602.

Smith NS and Shurin JB. 2010. Artificial structures facilitate lionfish invasion in marginal Atlantic habitats. Proc 63rd Gulf Caribbean Fish Inst 67: 342-44.

Strain EMA, Morris RL, Coleman RA, et al. 2017a. Increasing microhabitat complexity on seawalls can reduce fish predation on native oysters. Ecol Eng; doi.org/10.1016/j.ecoleng.2017.05.030.

Strain EMA, Olabarria C, Mayer-Pinto M, et al. 2017b. Eco-engineering urban infrastructure for marine and coastal biodiversity: which interventions have the greatest ecological benefit? J Appl Ecol 55: 426-41.

Stuart-Smith RD, Bates AE, Lefcheck JS, et al. 2013. Integrating abundance and functional traits reveals new global hotspots of fish diversity. Nature 501: 539-42.

Toft JD, Ogston AS, Heerhartz SM, et al. 2013. Ecological response and physical stability of habitat enhancements along an urban armored shoreline. Ecol Eng 57: 97-108.

Trebilco R, Dulvy NK, Stewart H, et al. 2015. The role of habitat complexity in shaping the size structure of a temperate reef fish community. Mar Ecol-Prog Ser 532: 197-211.

Wilhelmsson D, Yahya SA, and Öhman MC. 2006. Effects of high-relief structures on cold temperate fish assemblages: a field experiment. Mar Biol Res 2: 136-47.

\section{Supporting Information}

Additional, web-only material may be found in the online version of this article at

Figure 1. Selected examples of marine infrastructure. (a) Seawalls protect shorelines; (b) water-retaining "flowerpots" increase the biodiversity of seawalls; (c) fish associated with oil rigs; and $(d)$ eco-engineered tiles seeded with oysters.

Image credit:

(c) (C) rig2reefexploration.org

This article is protected by copyright. All rights reserved 
Figure 2. Eco-engineered seawall in Seattle, Washington. (a) Designed for juvenile salmon, the seawall includes (1) skylights to increase light penetration below the sidewalk, (2) complex walls to benefit greater numbers of invertebrate prey, and (3) marine mattresses to create a shallower migratory corridor. (b) View of the skylights from the sidewalk above.

Image credits:

(a) (C) U Washington

(b) (C) U Washington

Figure 3. Example of how marine infrastructure can be designed to benefit the commercially important yellowfin bream (Acanthopagrus australis) and yellowtail scad (Trachurus novaezelandiae) fisheries. Seagrass meadows (A) are facilitated in protected areas such as the leeward side of breakwaters. Seagrass and mangrove $(B)$ rehabilitation can promote juvenile bream $(C)$ forage and shelter. Connectivity with estuarine habitat could be facilitated by building patch reefs $(D)$ in open areas between the structure and nearby estuaries. Breakwater units have small-scale complexity $(E)$ to support prey items $(F)$ and reefs are deployed in areas adjacent to soft sediments $(G)$, thus increasing transition zones, habitat for yellowtail scad $(H)$, and foraging areas for bream (I). Objects of high vertical relief are built offshore of the structure to provide habitat and food $(\mathrm{J})$ for juvenile scad $(K)$. Symbols courtesy of the Integration and Application Network, University of Maryland Center for Environmental Science (www.ian.umces.edu/symbols).

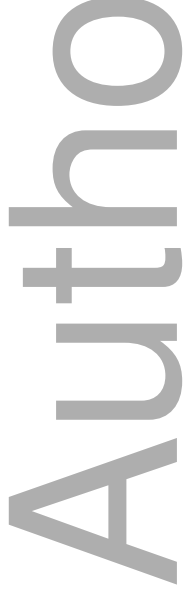




\section{Panel 1. Fish-smart seawalls: a case study}

Research in Seattle, Washington, presents one of the largest-scale eco-engineering projects for a target species of fish worldwide. The juveniles of threatened Pacific salmon species use the shoreline as a migratory corridor, and the need for a seawall upgrade provided an opportunity to enhance the habitat for juvenile fish and the invertebrates on which they feed (Figure 2; Munsch et al. 2017). Trials in the first stage of the project showed that more complex habitat enhancement panels, which incorporated steps and fins (protruding ledges at various angles), substantially increased the density of epibenthic prey species for juvenile salmon as compared to prey densities on flat tiles (Goff 2010). Replacing seawalls and riprap with two shoreline types (pocket beach and habitat bench) that created nearshore shallow areas also promoted greater densities of invertebrate prey and juvenile fish as well as incidence of fish feeding behavior (Toft et al. 2013). A pilot study also suggested that lightpenetrating panels facilitated greater use of areas under piers by juvenile salmon (Cordell et al. 2017). The seawall is still under construction; a 10-year monitoring program will be implemented following its completion.

\section{[SPS - please embed Figure 2 in Panel 1]}

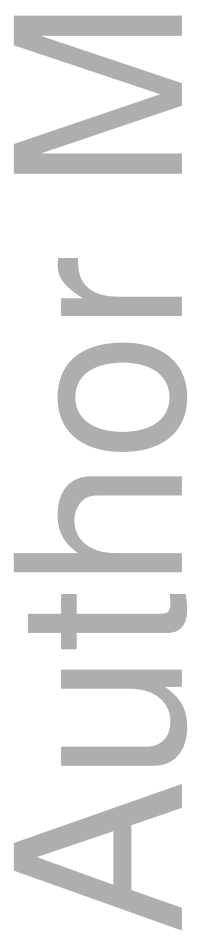




\section{Panel 2. How fishery species-specific habitat elements can be incorporated into the}

\section{design of marine infrastructure}

In this example, the structure is tailored toward two important fishery species: yellowfin bream (Acanthopagrus australis) and yellowtail scad (Trachurus novaezelandiae). Yellowfin bream is an estuarine and coastal species relying on seagrass and mangroves for juvenile stages, with adults commonly found over soft sediments near rocky reefs or over seagrass, where they forage for small fish, crabs, prawns, and worms (Kalatzis and Baker 2010). Yellowtail scad is a planktivorous, schooling, coastal pelagic species; adults are associated with rocky reefs and juveniles are often found at high vertical relief structures like wharves and over soft sediments (Rowling et al. 2010). By incorporating this knowledge into the design process, appropriate habitat elements can be included in the final structure (Figure 3). The modifications listed in Figure 3 are likely to have substantial benefits for bream, scad, and other groups as well. Where a feature is likely to have positive impacts for one group but negative impacts for another, managers will need to make decisions based on their own priorities.

[SPS - please embed Figure 3 in Panel 2]

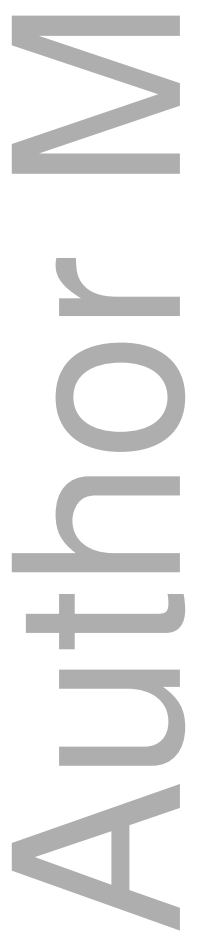


Table 1. Summary of the effects of the physical properties of artificial and natural reefs on fish assemblage measures

\begin{tabular}{|c|c|c|c|c|c|c|c|c|c|c|c|c|c|c|c|c|}
\hline \multirow{3}{*}{$\begin{array}{l}\text { Increasing the physical properties } \\
\text { listed below has resulted in: }\end{array}$} & \multicolumn{16}{|c|}{ Information is for the abundance of trophic/size groups: } \\
\hline & \multicolumn{2}{|c|}{ Biomass } & \multicolumn{2}{|c|}{ Abundance } & \multicolumn{2}{|c|}{ Sp richness } & \multicolumn{2}{|c|}{ Planktivores } & \multicolumn{2}{|c|}{ Herbivores } & \multicolumn{2}{|c|}{ Predators } & \multicolumn{2}{|c|}{ Large fish } & \multicolumn{2}{|c|}{ Recruitment } \\
\hline & A & $\mathrm{N}$ & A & $\mathrm{N}$ & A & $\mathrm{N}$ & A & $\mathrm{N}$ & A & $\mathrm{N}$ & A & $\mathrm{N}$ & A & $\mathrm{N}$ & A & $\mathrm{N}$ \\
\hline Reef or habitat patch area & $+/-$ & + & $+/-$ & + & + & $+/=$ & & & & & & & + & & $=/-$ & \\
\hline Edge/area ratio & & & + & & + & & & & & & & & - & & - & \\
\hline Inter-reef spi & + & & + & & + & - & & & $=$ & & $+1-$ & & $+/-$ & & + & \\
\hline Complexity (rugosity) & + & + & $+/=$ & $+/=$ & + & & & & & $+/-$ & & & - & & + & \\
\hline Vertical relief $^{\mathrm{a}}$ & & + & $+/=$ & + & $+/=$ & + & & + & & $+/-$ & & + & & + & & + \\
\hline Density of vertical structures & & + & & + & & + & & + & & $+/-$ & & + & & + & & + \\
\hline Density of holes & + & + & + & + & $+/=$ & & & & & & & & & + & & \\
\hline Diversity of hole size & & & $=$ & & $=$ & & & & & & & & & & & \\
\hline "Small" holes & & & + & & + & & & & & & & & & & & \\
\hline "Large" holes & + & + & + & + & + & & & & & & & & + & & - & \\
\hline Size of overhangs & & + & & + & & + & & + & & $+/-$ & & + & & + & & \\
\hline Density of structures ${ }^{b}$ & + & + & + & $+/-$ & & $+/=$ & & - & & $+/-1=$ & & $+/=$ & & & + & $+/-$ \\
\hline Diversity of structures ${ }^{b}$ & + & & + & + & $=$ & + & & & & & & & & & & \\
\hline
\end{tabular}

Notes: Artificial (A) and natural (N) reefs. Positive effect [+], negative effect [-], no effect [=]. Blank cells indicate no information was found. Symbols in

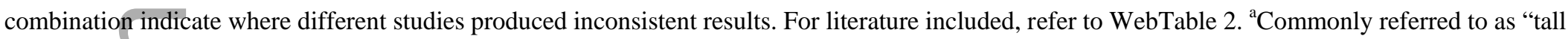
structures" in the natural reef literature. ${ }^{b}$ Refers to both abiotic and biotic structures.

This article is protected by copyright. All rights reserved 


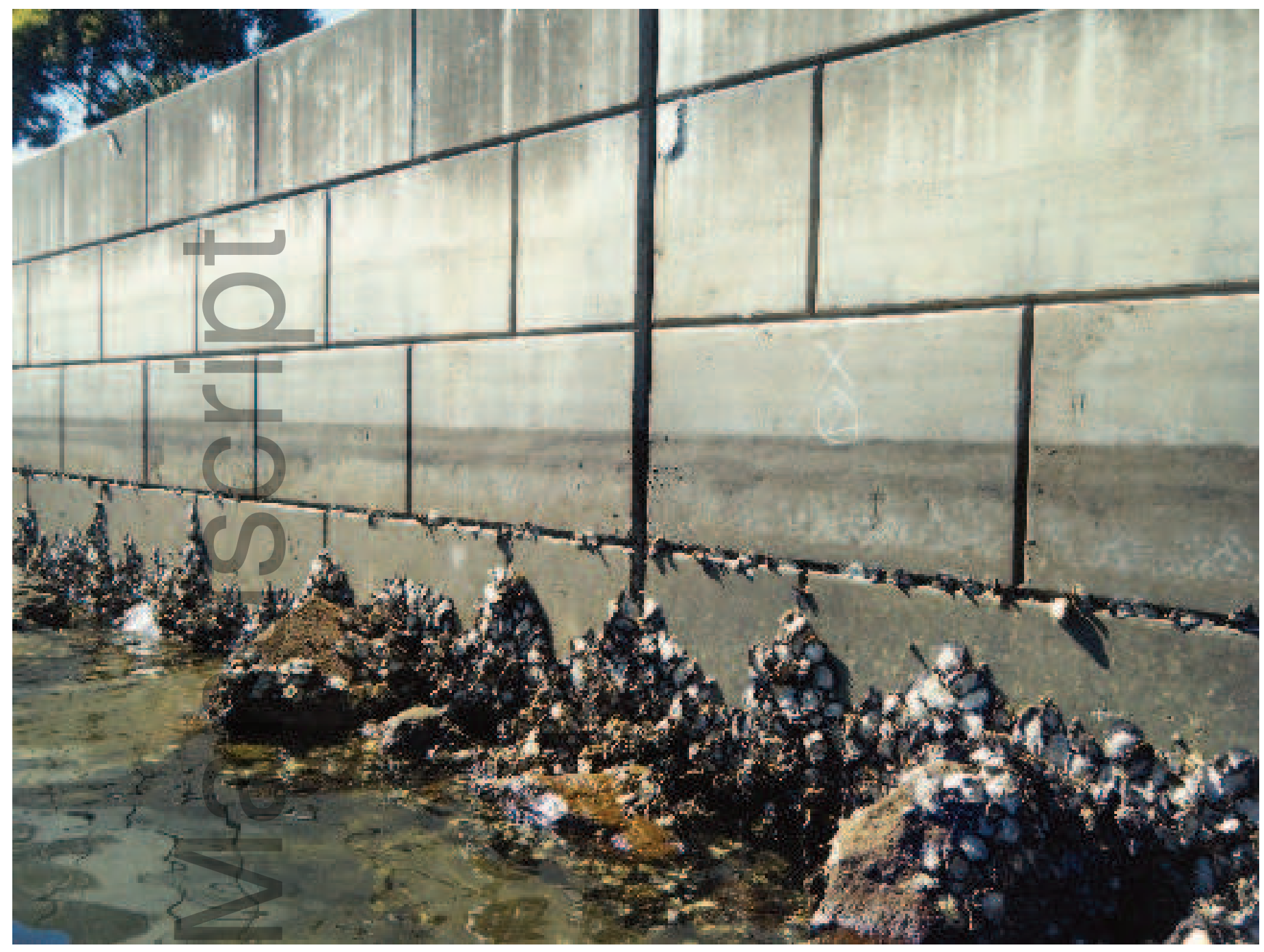

fee_1809_f1a.tif

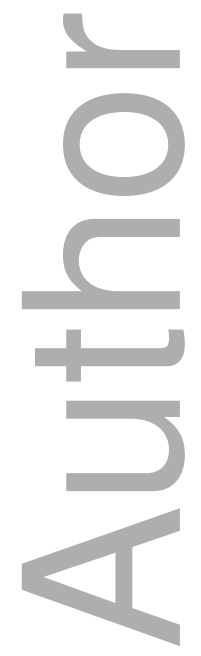

This article is protected by copyright. All rights reserved 

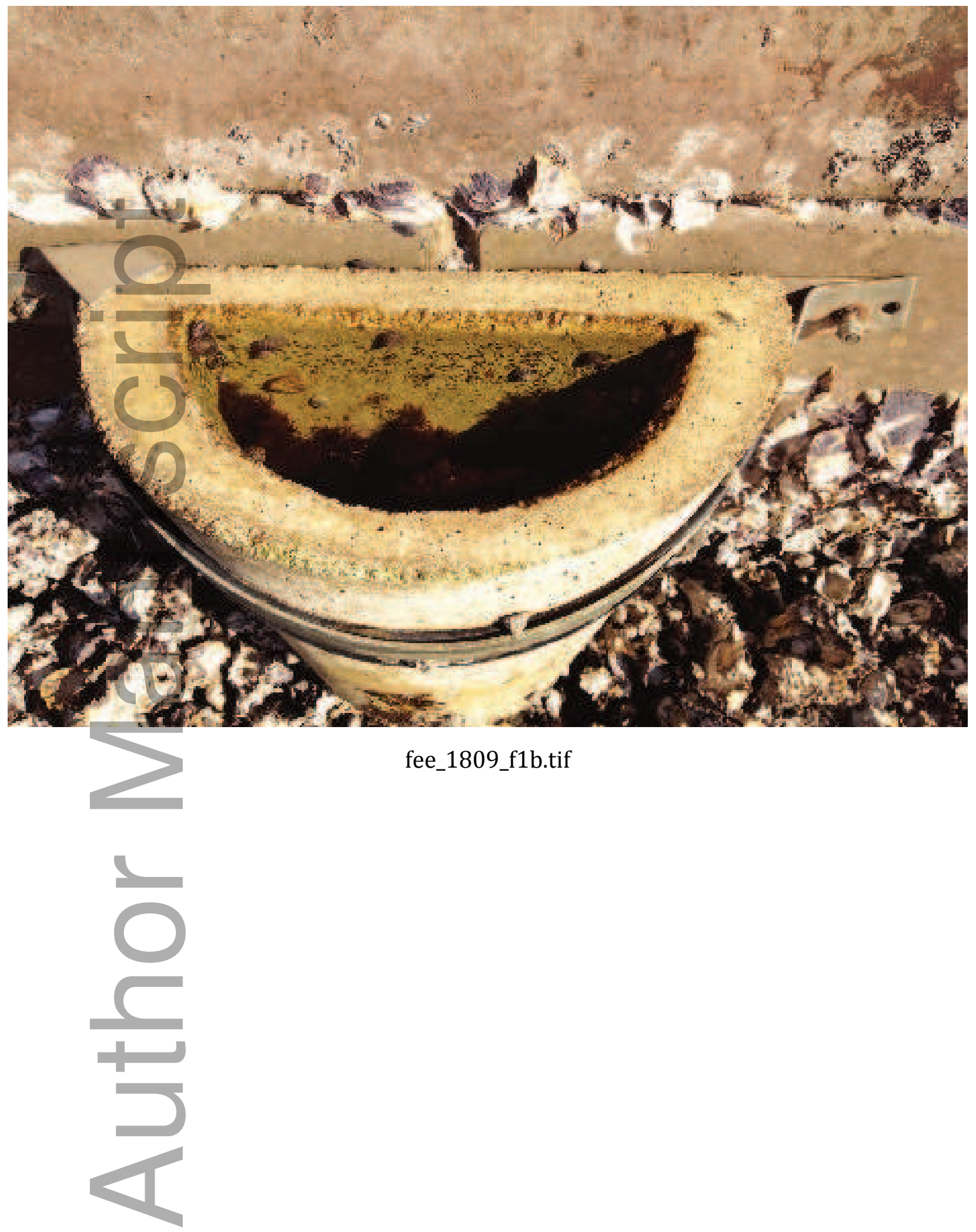

This article is protected by copyright. All rights reserved 

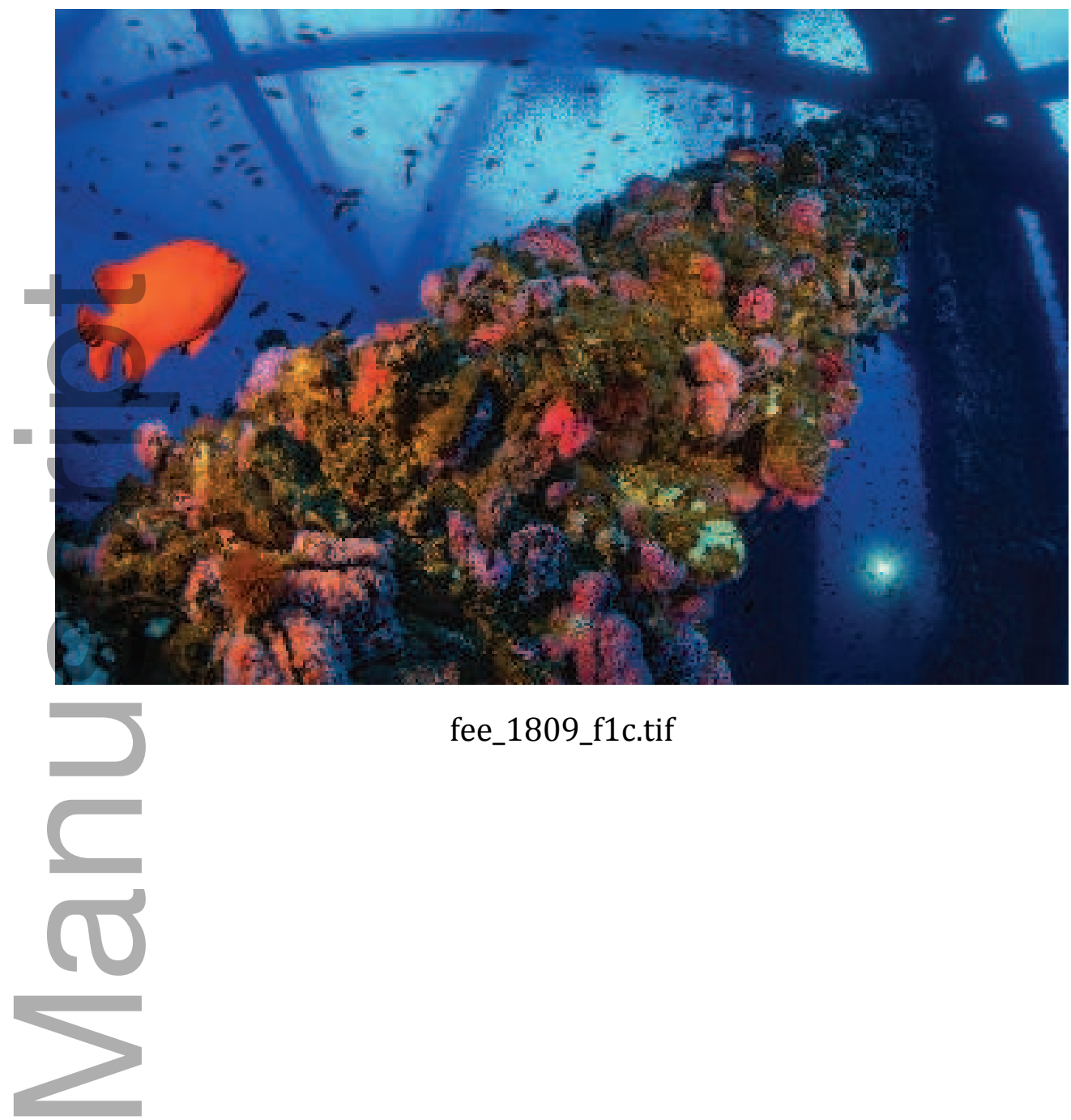

fee_1809_f1c.tif

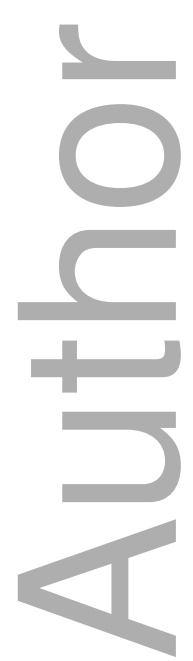



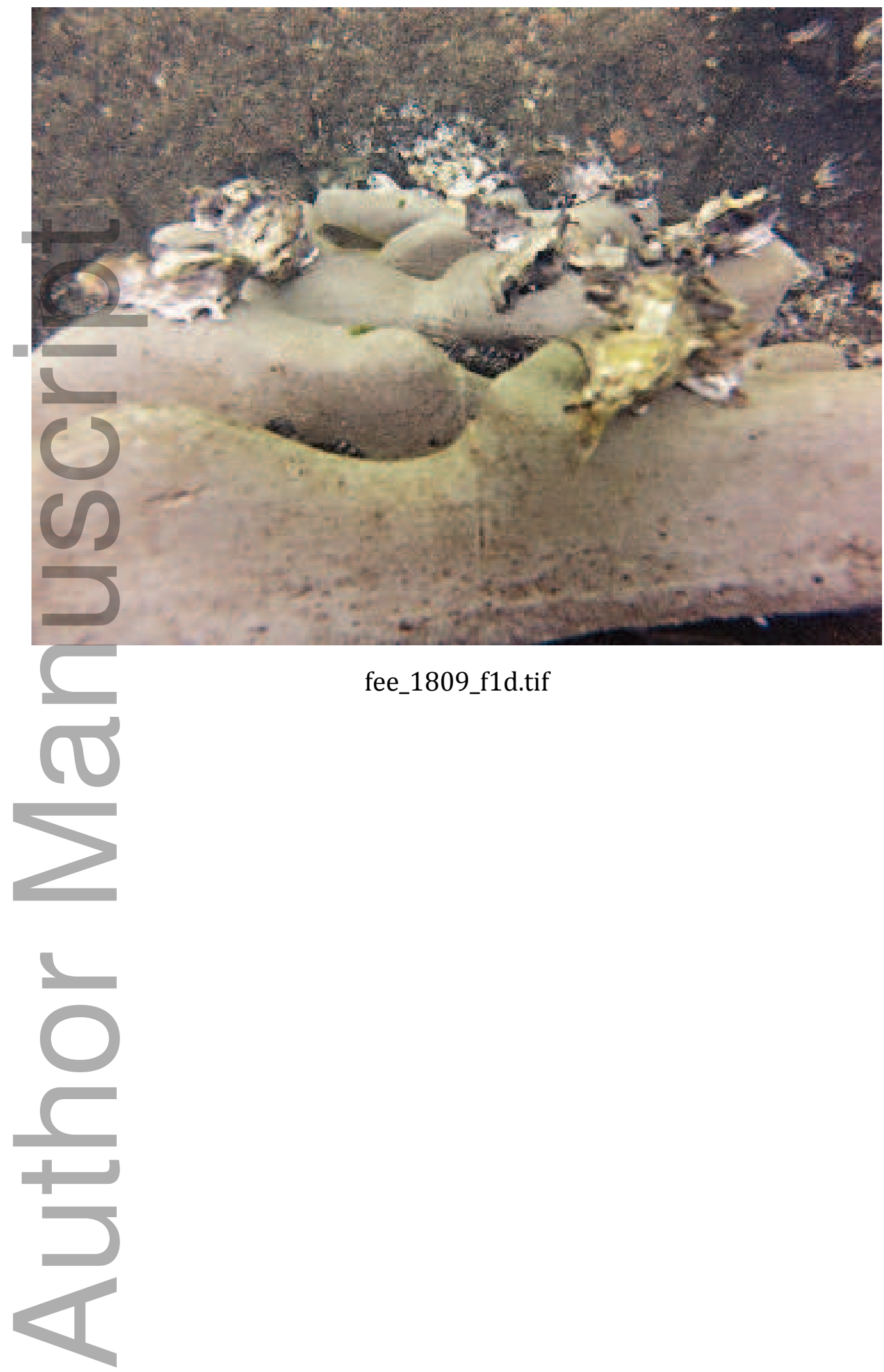


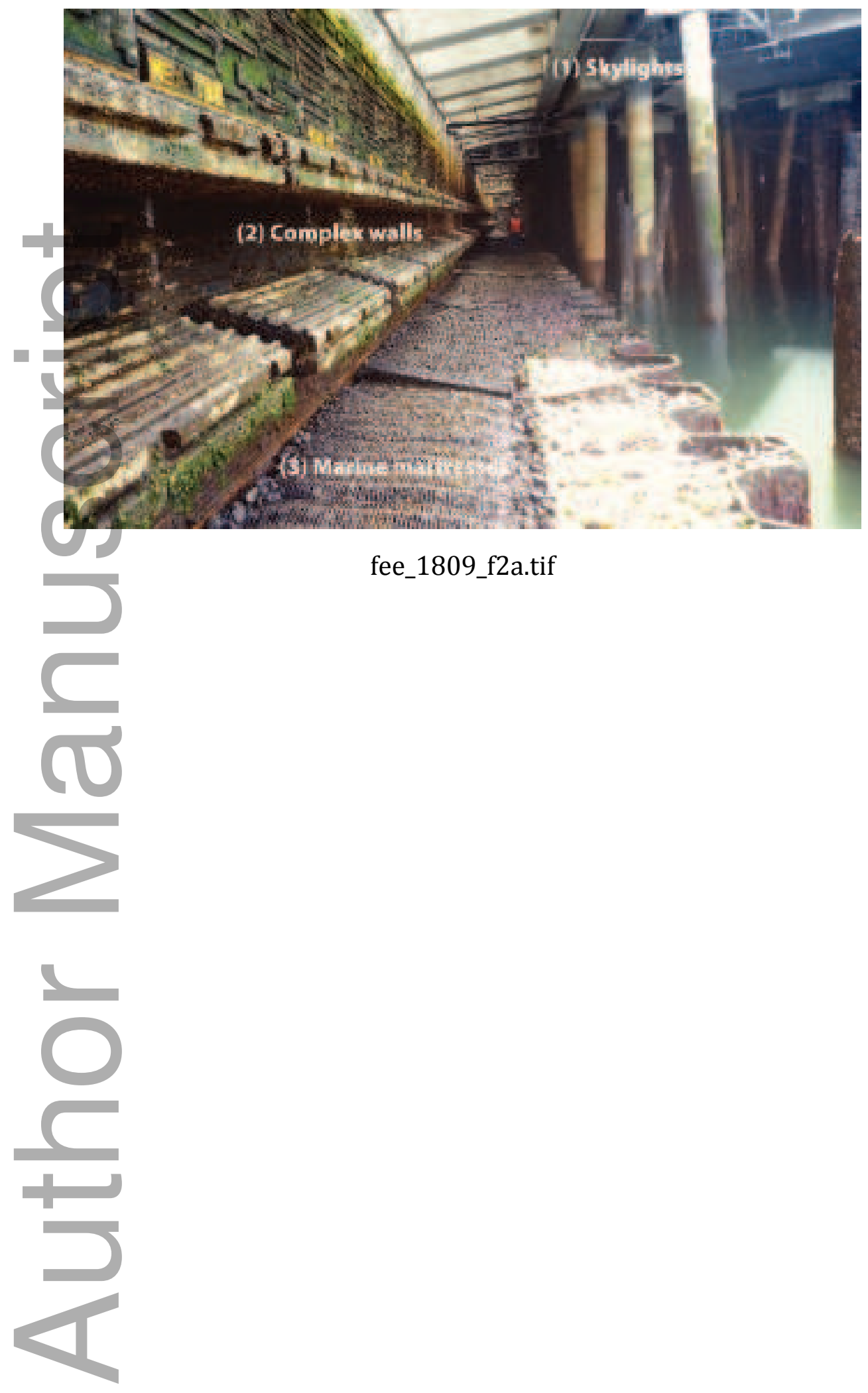

This article is protected by copyright. All rights reserved 

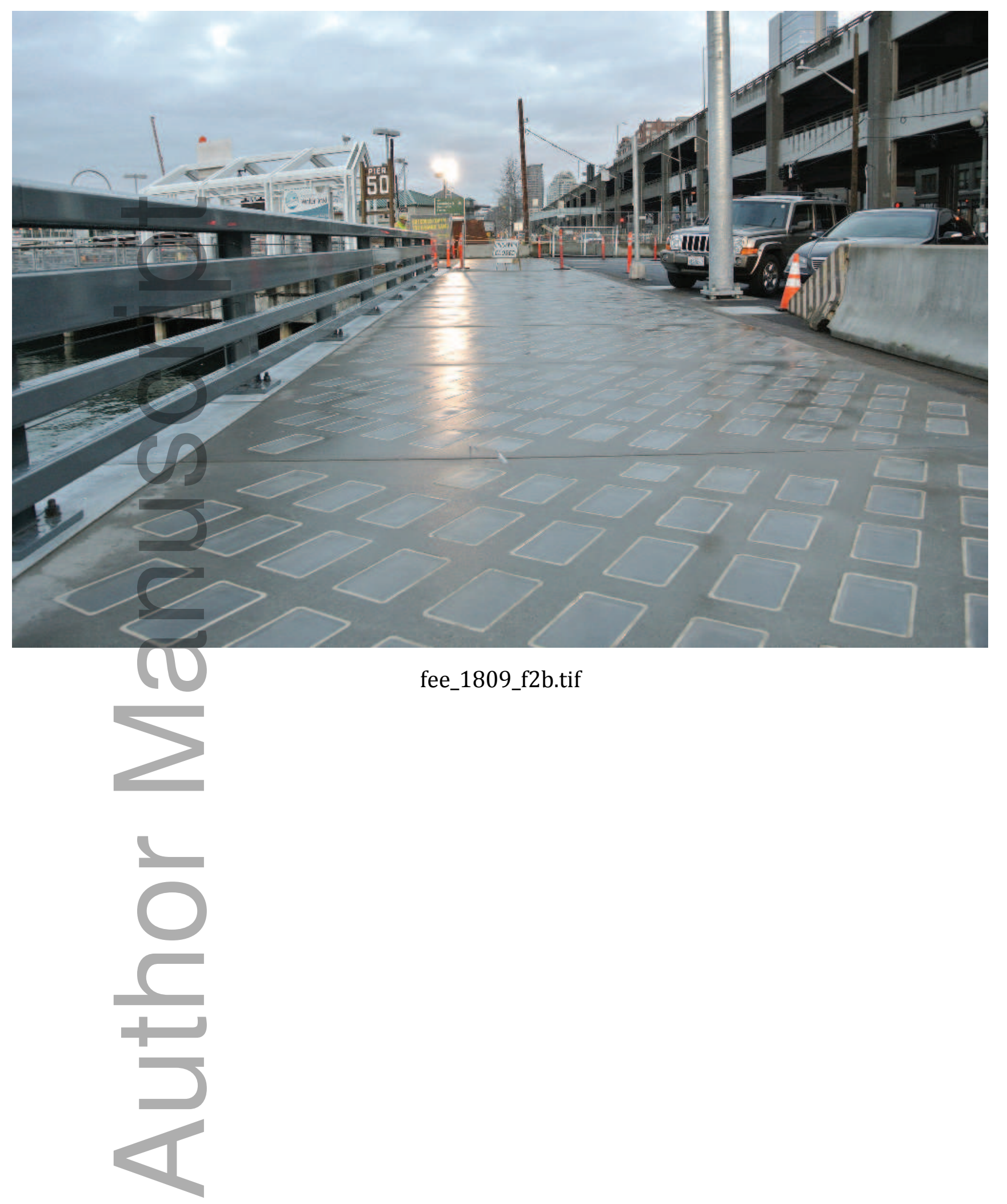

This article is protected by copyright. All rights reserved 

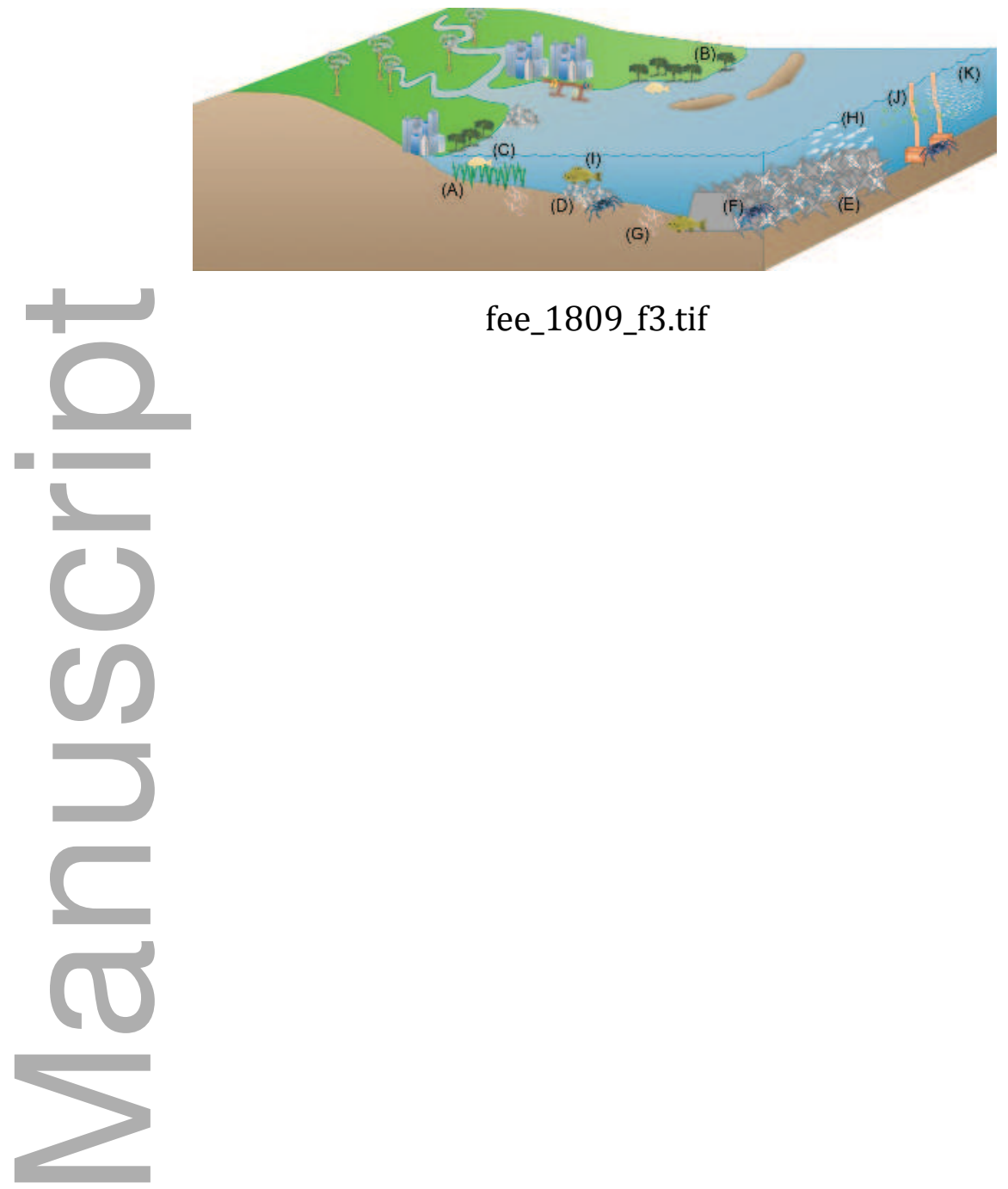

fee_1809_f3.tif

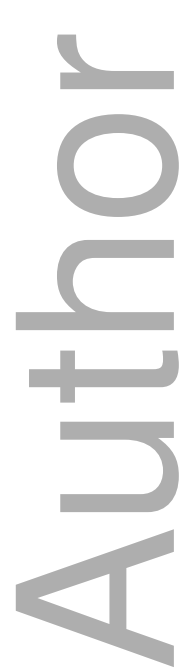

This article is protected by copyright. All rights reserved 


\section{University Library}

\section{- M M N E R VA A gateway to Melbourne's research publications}

Minerva Access is the Institutional Repository of The University of Melbourne

Author/s:

Morris, RL;Porter, AG;Figueira, WF;Coleman, RA;Fobert, EK;Ferrari, R

Title:

Fish-smart seawalls: a decision tool for adaptive management of marine infrastructure

Date:

2018-06-01

Citation:

Morris, R. L., Porter, A. G., Figueira, W. F., Coleman, R. A., Fobert, E. K. \& Ferrari, R. (2018).

Fish-smart seawalls: a decision tool for adaptive management of marine infrastructure.

FRONTIERS IN ECOLOGY AND THE ENVIRONMENT, 16 (5), pp.278-287. https://

doi.org/10.1002/fee.1809.

Persistent Link:

http://hdl.handle.net/11343/283965 